\title{
Effect of Hole Size on Flow Structure and Mixing Characteristic in a Multi-Hole Baffled Micro Combustor
}

\author{
Won Hyun Kim, Young Su Park, Seon Myeong Park, Tae Seon Park* \\ School of Mechanical Engineering, Kyungpook National University, Daegu, Republic of Korea \\ Email: *tsparkjp@knu.ac.kr
}

How to cite this paper: Kim, W.H., Park, Y.S., Park, S.M. and Park, T.S. (2017) Effect of Hole Size on Flow Structure and Mixing Characteristic in a Multi-Hole Baffled Micro Combustor. Journal of Applied Mathematics and Physics, 5, 7-16.

http://dx.doi.org/10.4236/jamp.2017.51002

Received: October 26, 2016 Accepted: December 28, 2016

Published: January 4, 2017

\begin{abstract}
Flow structure and mixing properties by the baffle shape are numerically studied for a baffled micro combustor. The baffle shape is changed by various fuel and hole sizes. The numerical simulations based on different geometric conditions are performed by using the Reynolds Stress Model. The fuel-air mixing is greatly affected by flow recirculations. The centrally located flow recirculation has an important role for the entire mixing performance. The results show that this feature depends on the baffle configurations, and the baffle with small air holes represents efficient characters.
\end{abstract}

\section{Keywords}

Micro Combustor, Baffle, Diameter Ratio, Flow Recirculation, Mixing, Secondary Flows

\section{Introduction}

In most combustion based micro power generation devices, the micro combustor is an important key factor to implement the energy converting from fuel contained chemical energy [1] [2]. Therefore, the entire system performance is determined by the combustion efficiency of combustor depending on the fuel-air mixing. However, for a micro combustor, the mixing of incoming fluids in a combustor is inherently weakened due to the flow laminarization and thus the combustion efficiency becomes worse. Especially, this feature is more obvious for a non-premixed combustor and results in a severe degradation for the whole system. Accordingly, a revised combustor for much higher fuel conversion efficiency is needed to solve such mixing problem.

To achieve this aim, many efforts have been devoted in recent [3]-[11]. Among them, one of effective way to get high mixing performance is to form a 
recirculation flow in a micro combustor by using multi-hole baffle plate [6]-[11]. For baffled micro combustor, large two parts flow recirculations are generated by the momentum difference of incoming fluids via the central fuel jet and annularly placed air jets. These features induce the complicate three dimensional flow structures provoking the fuel-air mixing and thus more homogeneous mixture can be obtained. Herein, the flow mixing is significantly varied depending on the evolution of flow recirculations. So, as many related studies have been addressed, the controlling flow recirculations by changing momentum difference and baffle configuration are an one of great interesting subject to develop a baffled combustor [6]-[11]. However, the investigation of the relation between recirculating flows and mixing efficiency is not explored.

In the present study, the baffle shape effect on the flow structure and mixing performance is numerically examined. Based on this, the optimum condition is proposed to get more homogeneously mixed fuel-air mixture. For that purpose, the hole size is selected as a key parameter to vary baffle configurations. Because various momentum difference can be drawn via reducing or enlarging each hole size under a constant inflow condition. From the result, the relation of flow recirculation and mixing performance are discussed by various baffle shapes.

\section{Numerical Methods}

The entire computational domain is composed of the inflow tube, baffle plate, and combustor as depicted in Figure 1. Details of geometric conditions are summarized in Table 1. The inlet of central jet and annular tube is imposed by the fully developed velocity and turbulent profile based on the preliminary computation results of inflow tube. Incoming fluids of center jet and annular tube are selected as the methane and air, respectively. For comparison, the inlet mass flow rate is maintained as the air-fuel ratio of 17.11 for selected all cases. The pressure outlet and adiabatic wall $(300 \mathrm{~K})$ boundary condition are adopted. To see the baffle shape effect, the hole size is changed for seven cases depending on the diameter ratio ( $\left.D R=D_{f} / D_{o}\right)$.

For steady and incompressible turbulent flows, the continuity and momentum equation are as follows [12]:

$$
\frac{\partial\left(\rho U_{i}\right)}{\partial x_{i}}=0
$$

Table 1. Details of geometric conditions.

$\begin{array}{cc}\text { Combustor diameter, } \mathrm{D} & 2.80 \mathrm{~mm} \\ \text { Radial air hole position, } \mathrm{r}_{\mathrm{a}} & 0.80 \mathrm{~mm} \\ \text { Baffle thickness, } \mathrm{b}_{\mathrm{t}} & 0.04 \mathrm{~mm} \\ \text { Inner diameter of inflow tube, } \mathrm{D}_{\mathrm{i}} & 0.62 \mathrm{~mm} \\ \text { Combustor length, } \mathrm{L}_{\mathrm{a}} & 40.0 \mathrm{~mm} \\ \text { Inflow tube length, } \mathrm{L}_{\mathrm{i}} & 5.60 \mathrm{~mm} \\ \text { Fuel (=air) hole diameter, } \mathrm{D}_{\mathrm{f}}\left(=\mathrm{D}_{\mathrm{a}}\right) & 0.1-0.4 \mathrm{~mm} \\ \text { Diameter ratios, } \mathrm{DR}=\mathrm{D}_{\mathrm{f}} / \mathrm{D}_{\mathrm{a}} & 0.25-4.0\end{array}$




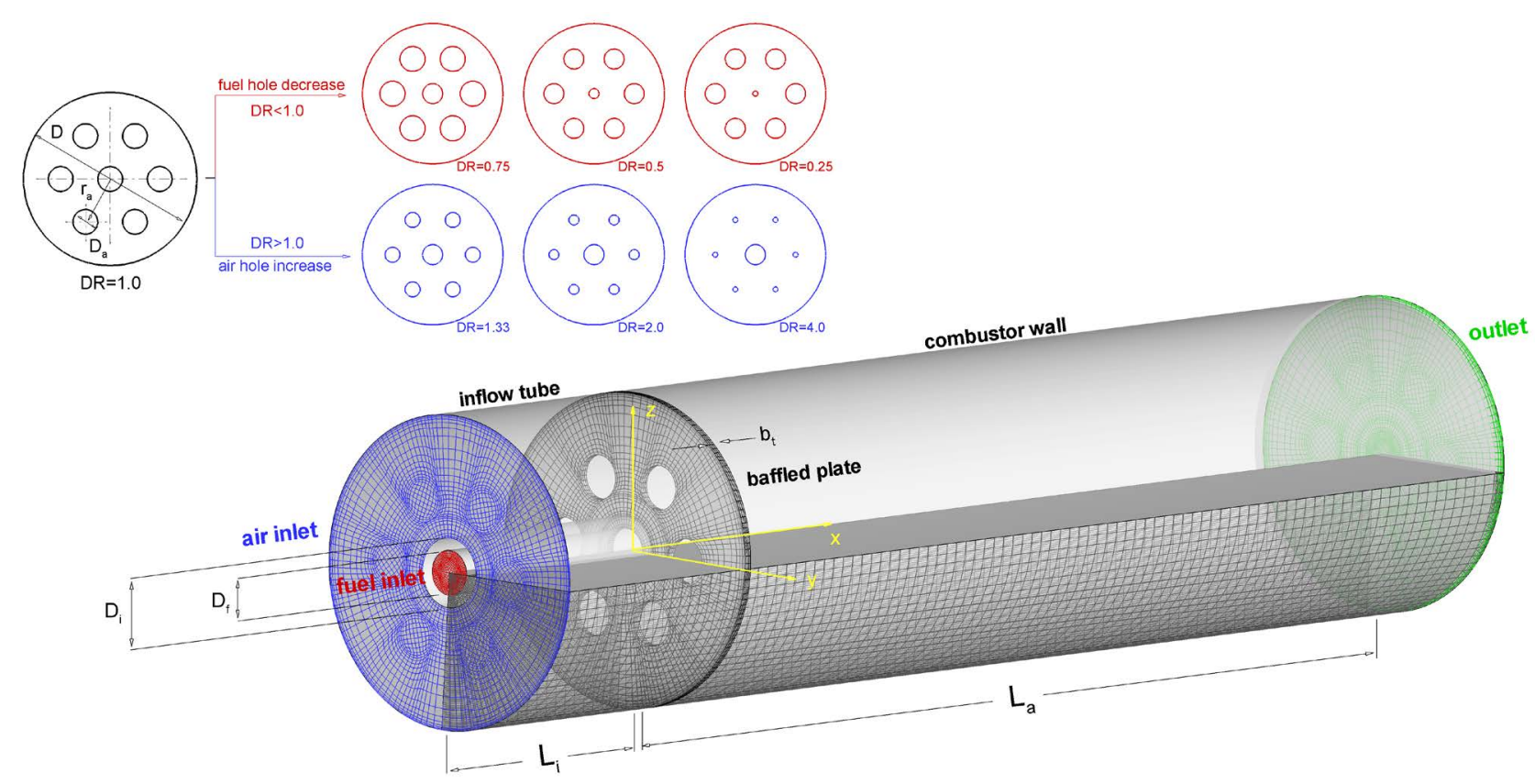

Figure 1. Computational domain and baffle configurations.

$$
\frac{\partial\left(\rho U_{i} U_{j}\right)}{\partial x_{i}}=-\frac{\partial P}{\partial x_{j}}+\frac{\partial}{\partial x_{i}}\left(\mu \frac{\partial U_{i}}{\partial x}-\rho \overline{u_{i}^{\prime} u_{j}^{\prime}}\right)
$$

where $U_{i}, P, \mu, \rho$, and $\overline{u_{i}^{\prime} u_{j}^{\prime}}$ are the velocity components, pressure, viscosity, density, and Reynolds stress, respectively. In Equation (2), is needed to an additional modeling to solve it. Among various turbulent closures, the Reynolds Stress Model is used and expressed as follows [12]:

$$
\frac{\partial}{\partial x_{k}}\left(\rho U_{k} \overline{u_{i} u_{j}}\right)=D_{i j}+P_{i j}+\phi_{i j}+\varepsilon_{i j}
$$

where $D_{i j}, P_{i j}, \phi_{i j}$, and $\varepsilon_{i j}$ represent the turbulent diffusion and production, pressure-strain, and dissipation term, respectively. For simplicity, details of modeling and related constants for each term are omitted. And the species transport equation is additionally solved to evaluate a passive scale mixing and it is written as follows [12]:

$$
\frac{\partial}{\partial t}\left(\rho U_{j} Y_{i}\right)=-\frac{\partial}{\partial x_{j}} J_{i}+R_{i}
$$

where $Y_{i}, J_{i}$, and $R_{i}$ denote the mass fraction, diffusion flux, and net mass rate of species $i$, respectively. Numerical simulations are employed by the Ansys FLUENT 13.0 [12]. The SIMPLEC algorithm is used for the pressure-velocity coupling and the second-order upwind scheme is applied to solve all equations under the convergence criteria of $10^{-6}$. For saving the computational costs, the proper grid resolution is selected by checking grid dependency for 250,000, 400,000, 600,000, and 900,000 control volumes (CVs). Figure 2 shows the distribution of streamwise velocity and density at the center axis for different CVs. Here, $U_{c}$ means the streamwise velocity at the baffle exit center. As can be seen 


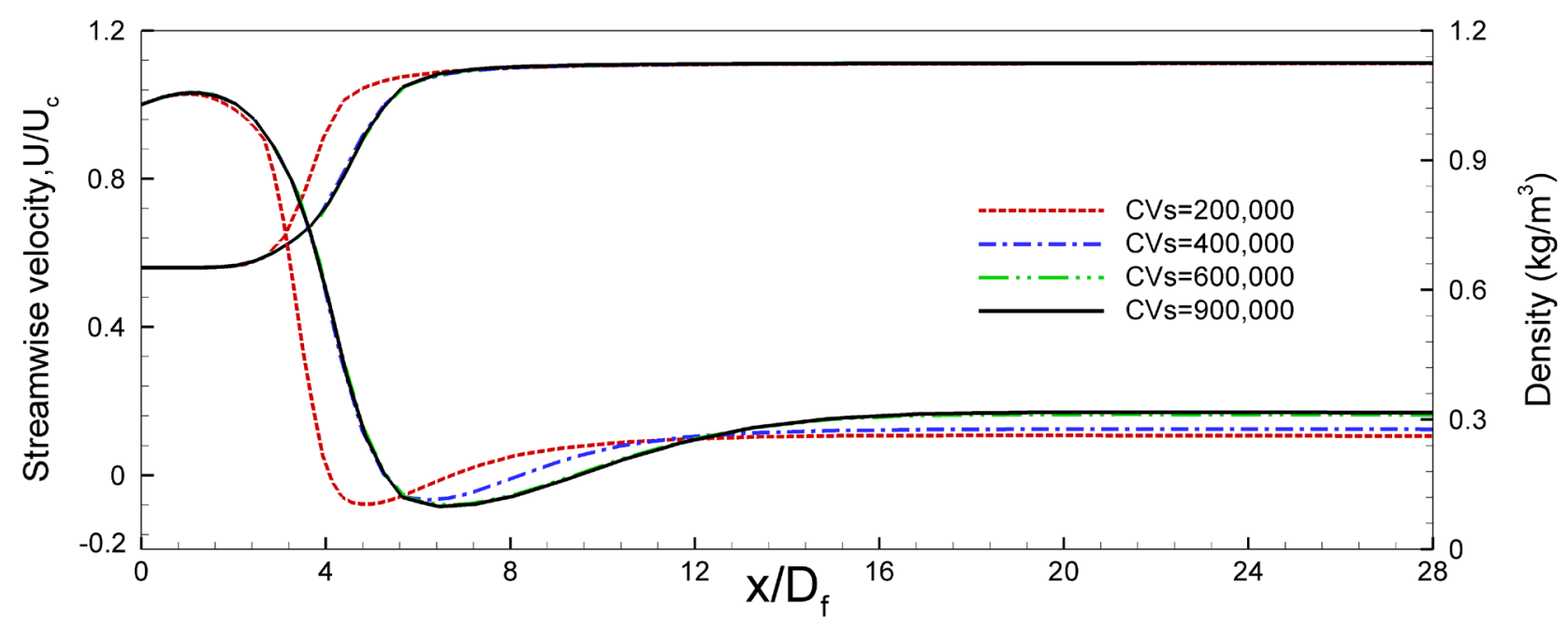

Figure 2. Grid dependency for different control volumes.

in the figure, the streamwise velocity and density profile appear almost identical more than 600,000 CVs. Based on this result, the final grid resolution is maintained an approximate of $600,000 \mathrm{CVs}$.

In order to validate the numerical method, the present $R S M$ is compared with the numerical result for $\kappa-\varepsilon-f_{\mu}$ model and LES of Choi and Park [9] due to the lack of an available experiment data as the same current geometric condition. Figure 3 plots the vector map of $x-z$ plane to see the evolution of flow recirculations by different turbulence models. Because of the turbulence closures difference, the size and position of reproduced recirculating flows are somewhat dissimilar to each model, but the overall trend of flow development is well predicted. Therefore, the numerical simulation implemented by a current method can be seen as reasonable.

\section{Results and Discussions}

\subsection{Flow Structure and Mixing for DR $=\mathbf{1 . 0}$}

According to the previous studies [6]-[11], the current baffle geometry induces the momentum difference between the incoming fuel jet and air flow passing by six air holes and between the air stream and ambient flow in a combustor. As a result of this, separated two parts of flow recirculation zones are generated. These features are dominant flow structure in determining the entire flow mixing. Therefore, the mixing mechanism properties coupled to the evolution of flow structure are needed to investigate previously before further discussion of the baffle shape effect.

Firstly, in order to see the evolution of flow structure in a baffled micro combustor, Figure 4(a) shows the streamlines of $x-y$ and $x-z$ plane with the streamwise velocity contour for $D R=1.0$. Looking at the figure, large two parts of flow recirculations are to be found. That is, the wallward motions of flow recirculation near the baffle and the centrally located recirculating flow to a certain distance downstream from the baffle are formed separately. These characteristic 


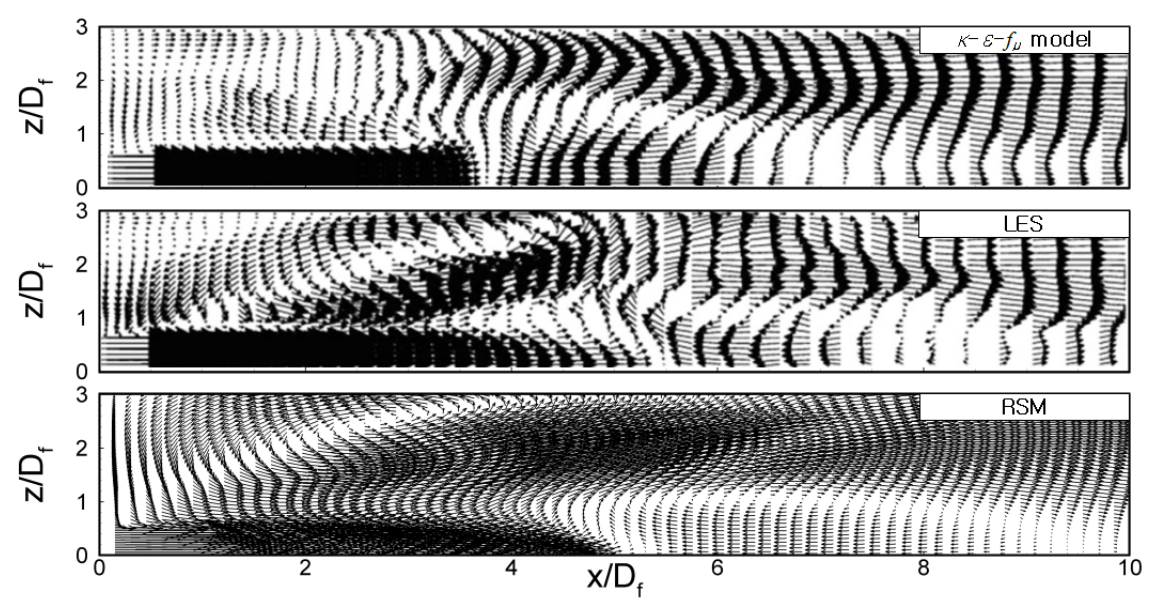

Figure 3. Comparison of vector plot for different turbulence models.
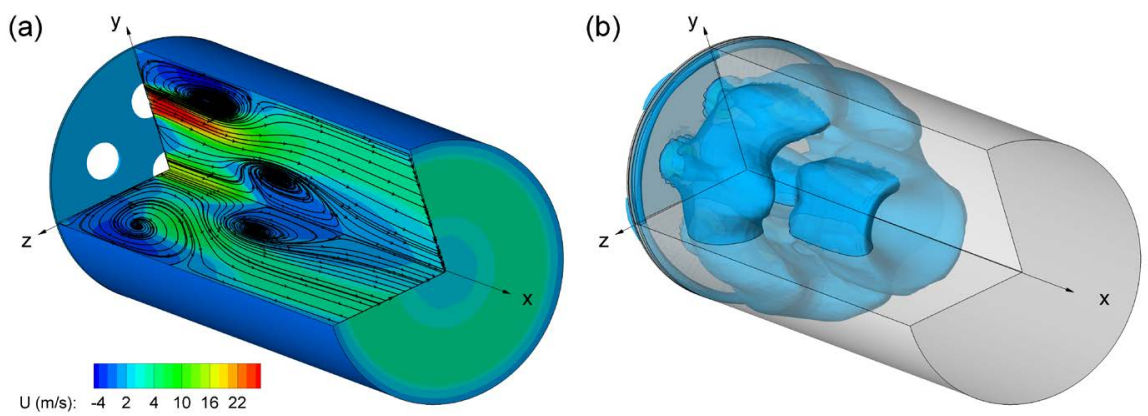

Figure 4. (a) streamlines of $x-y$ and $x-z$ plane with streamwise velocity contour; (b) isosurface of $Q=-0.05$.

features contain strongly circulated radial flows, so large scale vortical structures are taken place as plots in Figure 4(b). To identify such vortical motions, the second invariant of the velocity gradient tensor, i.e. Q-criterion is used and the iso-surface of $\mathrm{Q}=-0.05$ is presented. Here, the $\mathrm{Q}$-criterion is defined as $\mathrm{Q}=$ $0.5\left(\Omega_{i j} \Omega_{i j}-S_{i j} S_{i j}\right) \times D_{f}^{2} / U_{c}^{2}$ where $S_{i j}$ and $\Omega_{i j}$ mean the strain rate and vorticity tensor, respectively [13]. From its definition, the positive value of Q-criterion represents the vortical motion by the rotation tensor and it is well described in a current baffled combustor. As addressed by the previous studies [6]-[11], flow recirculations with large scale vortical structures provoke the development of complicated three dimensional flows. Under this process, the mixing of fuel and air becomes more homogenous. This can be confirmed through the following figure.

To examine the mixing process by flow recirculations, Figure 5 shows the vector plot of $x-y$ plane, mixedness $(M)$, and secondary flows magnitude $\left(S_{e c}\right)$. Herein, a passive scale mixing is quantitatively evaluated by following [14]:

$$
M=\frac{\int\left[Y_{C_{4}}(x, y, z)-\bar{Y}_{C_{4}}(x, y, z)\right] d y d z}{\int\left[Y_{C_{4}}(0, y, z)-\bar{Y}_{C_{4}}(0)\right] d y d z}
$$

where $\bar{Y}_{\mathrm{CH}_{4}}$ denotes the mean mass fraction of methane at the $y-Z$ plane. 


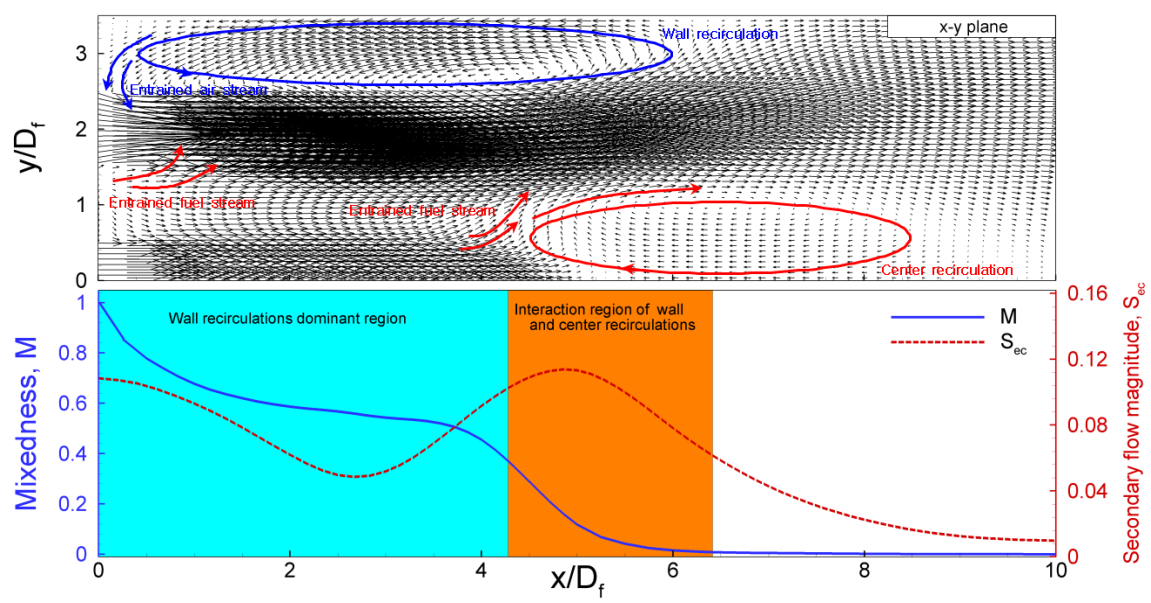

Figure 5. Vector plot of $x-y$ plane and distribution of mixedness and secondary flows magnitude to the streamwise direction.

According to its definition, more homogenous mixing state is to be achieved when $M$ becomes closer to 0 . And $S_{e c}$ is computed from $S_{e c}=\sqrt{V^{2}+W^{2}} / U_{c}$. In the figure, $M$ is initially decreased to $x / D_{f}=4.0$ where $W R F$ appears only. This means that $W R F$ is a dominant flow structure resulting in the flow mixing for that region. After that, $M$ is steeply reduced for $x / D_{f}=4.3 \sim 6.4$ where the interaction of $W R F$ and $C R F$ is actively occurred. These features are closely related to the entrained flow by recirculations. Namely, CRF and WRF make the entrained flow toward the center axis and combustor wall as displayed by the added arrow in the vector plot. Due to this, the radial secondary flows motion is more provoked and its maximum value is about $12 \%$ versus the momentum of fuel jet at the baffle exit. Accordingly, $M$ is fastly decayed under a comparatively high value of $S_{e c}$ for $x / D_{f}=0.0 \sim 1.0$ and $x / D_{f}=4.0 \sim 6.0$. Especially, it is to note that the complete mixing is to be achieved before the center of CRF. From this result, we can conclude that $C R F$ is an important factor to develop more efficient and compact combustor. Because, if CRF would be removed, $M$ and $S_{e c}$ values are monotonically decreased. This means that much longer combustor length is needed to obtain perfectly mixed state of incoming fuel and air into a combustor.

\subsection{Diameter Ratio Effect}

As discussed in previous section, the mixing properties in a micro combustor are seriously dependent on the evolution of flow recirculations. Thus, the modified flow structure by the variance of momentum difference has a significant effect on the entire mixing performance. To confirm this, the fuel and air hole size are changed for various diameter ratios. Because, in a current baffle geometry, various momentum differences can be drawn by the resizing of fuel or air hole. Based on the same fuel and air hole for $D R=1.0, D R=0.75,0.5,0.25$ for fuel hole decreased cases and $D R=1.33,2.0,4.0$ for the air hole reduced cases are additionally selected.

In order to see the vortical structure (VS ) variance induced by flow recircula- 
tions, the iso-surface of $\mathrm{Q}=-0.05$ for different diameter ratios are presented in Figure 6. As can be seen in the figure, the influence of baffle shape on the reproduced flow structure is very clear. For $D R<1.0, C R F$ is not formed dissimilar to $D R=1.0$, so there is no centrally located $V F$. It is mainly attributed to the strongly penetrated fuel stream with the decrease of fuel hole. Instead, near wall VF is expanded to downstream by more passed and circulated flow in a streamwise direction. On the other hand, the wallward motion of $V F$ is almost unchanged for $D R>1.0$, but the $V F$ in the vicinity of center axis is more enlarged and pulled upstream. From this feature, the interaction is more enhanced as can be explained in Figure $\mathbf{5}$ and thus the flow mixing becomes better than $D R=1.0$.

For detailed comparisons, the variance of flow recirculations depending on $D R$ is needed to quantify. Toward this end, the variations of width and height for $C R F$ and $W R F$ by $D R$ are compared in Figure $7(a)$. As added in the figure, the width and height of each flow recirculation are defined as the streamwise and vertical length across the center, respectively. And Figure 7(b) shows the mixing length $\left(L_{M}\right)$. Herein, $L_{M}$ is defined as the normal distance to $M=0.01$ which is achieved $99 \%$ mixing.

In Figure 7(a), CRF appears for DR $>1.0$ and it is expanded to a streamwise and radial direction as the air hole is scaled down. Also, the initially developed location moves upstream and thus the interaction with WRF becomes more intensified. This spatial enlargement of $C R F$ and subsequently reinforced interaction between recirculations can induce more entrained flows and secondary motions. Due to this feature, the mixing ability is more enhanced for $D R>1.0$ based on $D R=1.0$. Among them, $D R=4.0$ shows the best mixing performance with the shortest mixing length. It is mainly due to the largest developed CRF with its intensified interaction with $W R F$. Moreover, the width and height of WRF is also increased, but its change is negligible compared to the variance of $C R F$.

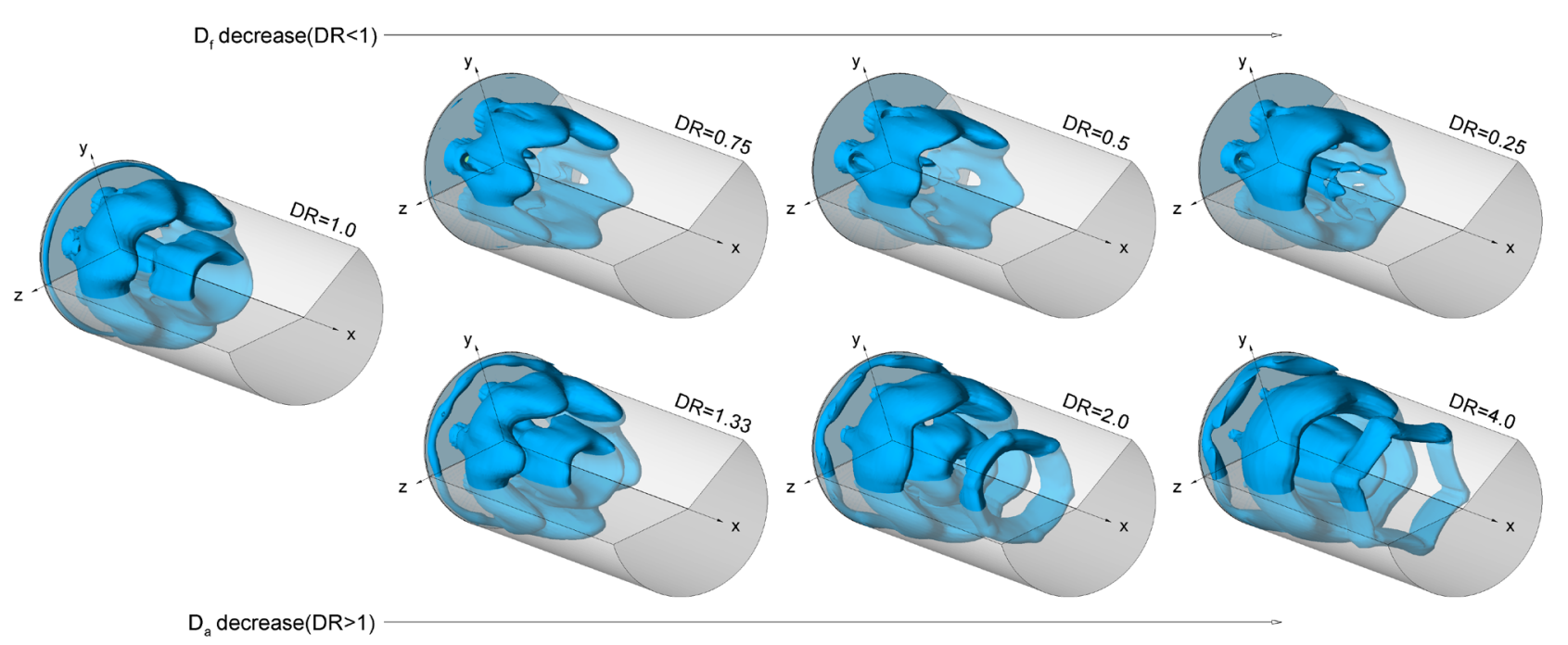

Figure 6. Iso-surface variance of $\mathrm{Q}=-0.05$ for different diameter ratios. 
(a)

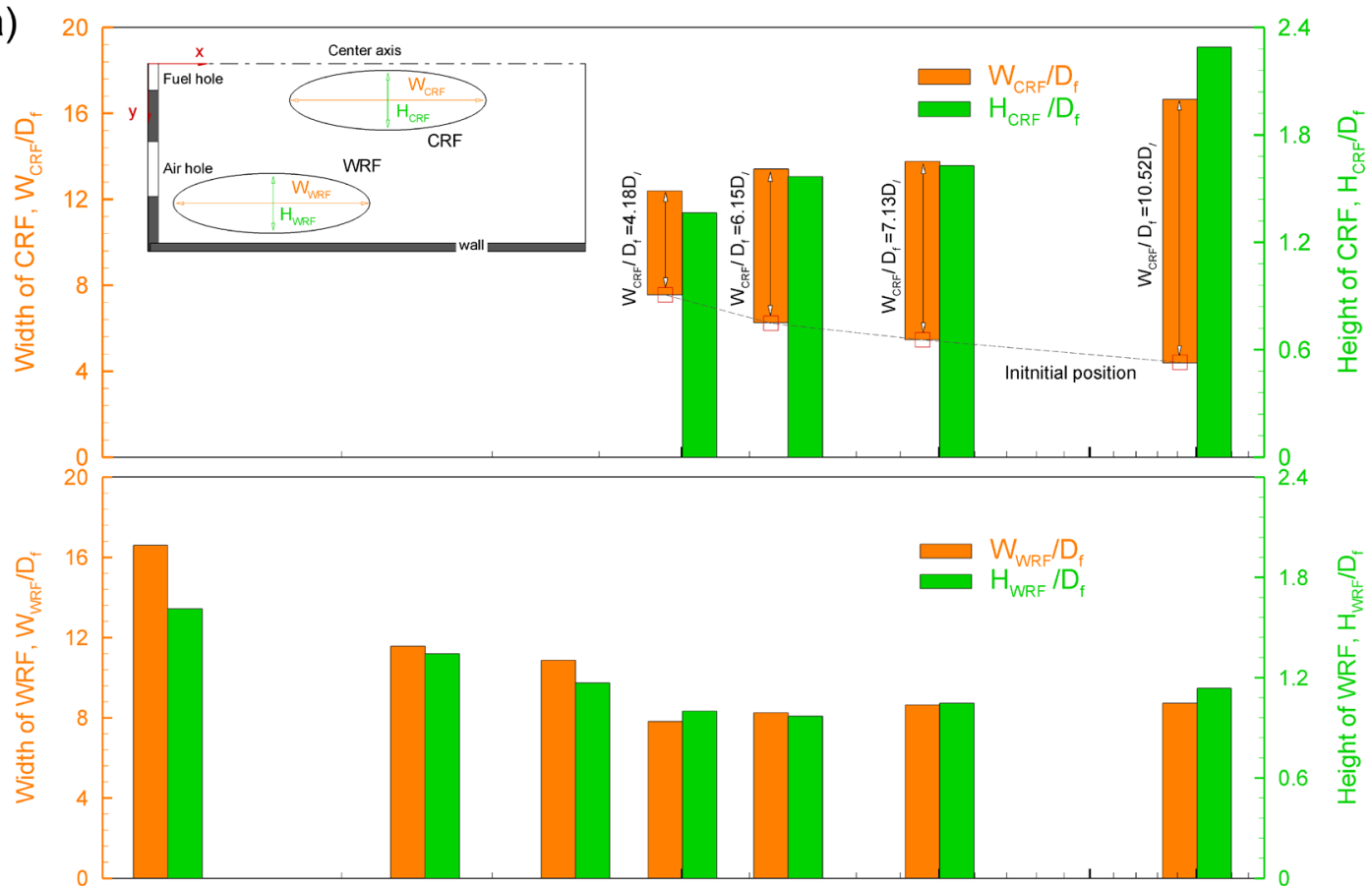

(b)

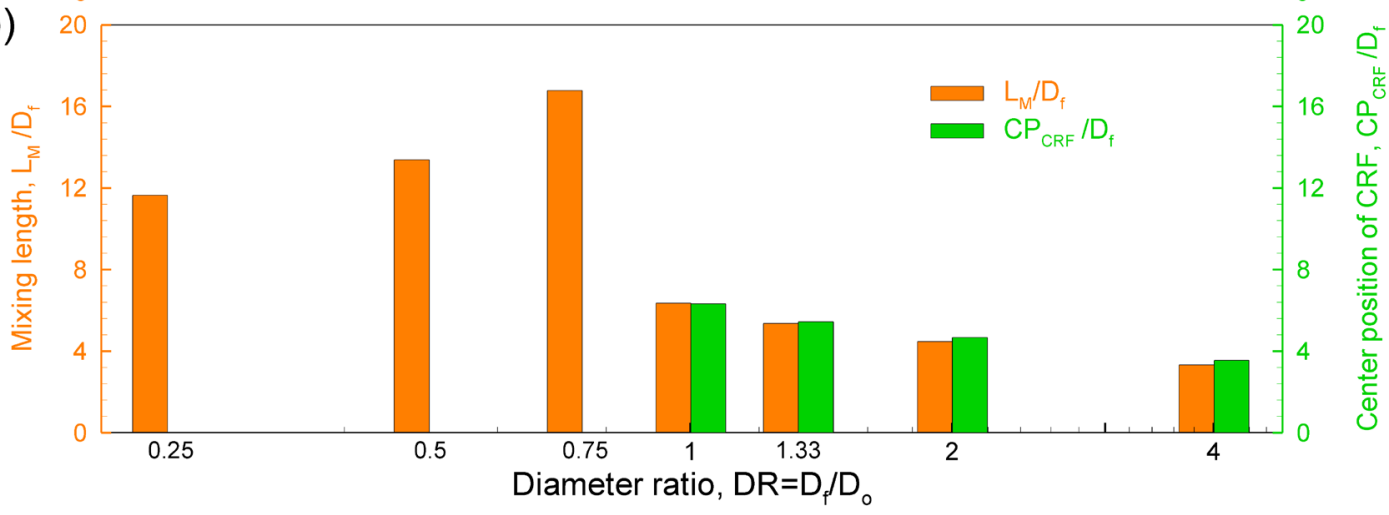

Figure 7. Comparison of (a) flow recirculation variance, (b) mixing length by diameter ratio.

For $\mathrm{DR}<1.0, W R F$ is seriously varied depending on DR. The highly ejected fuel stream inversely proportional to the fuel hole size hinders to generate $C R F$, but it contributes to make more spatially enlarged WRF. For those cases, the flow mixing is becomes fast for smaller fuel hole size. However, compared to $D R=1.0$, further longer combustor length is required to obtain completely mixed flows. On the other hand, $99 \%$ mixing is to be achieved near the middle of $C R F$ and this location is further anchored upstream as the air hole decreases. Especially, almost a half of combustor size is required for $D R=4.0$. So, to develop a more efficient micro combustor, it is desirable to make for higher momentum of air flow than that of the fuel jet. In this point, the selection of smaller air hole in a baffled combustor is an one of effective alternative.

\section{Conclusions}

For a baffled micro combustor, recirculating flow and mixing characteristics depending on the baffle shape were investigated. The fuel and air hole size of the 
baffle were changed by various diameter ratios. For the baffle with constant sized holes, the overall flow mixing was governed by the evolution of flow recirculations with large scale vortical structure. The mixing was provoked by the entrained secondary flows due to the wall recirculations near the baffle plate. As the flow develops downstream, the interaction between the wall and center recirculations is reinforced within a narrow zone. Then, the complete mixing was to be achieved before the middle of center recirculation. From this result, it was ascertained that the center recirculation is a decisive factor for the mixing performance.

So, the relation between the variation of center recirculation and the flow mixing characteristics was investigated by changing fuel and air hole size. For $D R<1.0$, the center recirculation was not formed, whereas the wall recirculations were spatially enlarged as the fuel hole decreased. For those cases, relatively longer combustor length was required to obtain completely mixed mixture compared to $D R=1.0$. On the contrary, it was possible to make more minimized combustor with highly mixed state of incoming fluids as the air hole reduced. This was mainly due to the strongly developed center recirculation for $D R>1.0$ and $D R=4.0$ had the largest center recirculation with the fastest flow mixing. As a result, it was confirmed that the better mixing performance in a baffled combustor is obtained by the air stream of higher momentum than that of the fuel stream.

\section{References}

[1] Chia, L.C. and Feng, B. (2007) The Development of a Micropower (Micro-Thermophotovoltaic) Device. Journal of Power Sources, 165, 455-480. https://doi.org/10.1016/j.jpowsour.2006.12.006

[2] Ju, Y. and Maruta, K. (2011) Microscale Combustion: Technology Development and Fundamental Research. Prog. Energy Combust. Sci, 37, 669-715.

https://doi.org/10.1016/j.pecs.2011.03.001

[3] Bagheri, G., Hosseini, S.E. and Wahid, M.A. (2014) Effects of Bluff Body Shape on the Flame Stability in Premixed Micro-Combustion of Hydrogen-Air Mixture. Applied Thermal Engineering, 67, 266-272.

https://doi.org/10.1016/j.applthermaleng.2014.03.040

[4] Wan, J., Fan, A., Maruta, K., Yao, H. and Liu, W. (2012) Experimental and Numerical Investigation on Combustion Characteristics of Premixed Hydrogen/Air Flame in a Micro-Combustor with a Bluff Body. International Journal of Hydrogen and Energy, 37, 19190-19197. https://doi.org/10.1016/j.ijhydene.2012.09.154

[5] Fan, A., Wan, J., Liu, Y., Pi, B., Yao, H. and Liu, W. (2014) Effect of Bluff Body Shape on the Blow-Off Limit of Hydrogen/Air Flame in a Planar Micro-Combustor. Applied Thermal Engineering, 62, 13-19. https://doi.org/10.1016/j.applthermaleng.2013.09.010

[6] Yahagi, Y., Sekiguti, M. and Suzuki, K. (2007) Flow Structure and Flame Stability in a Micro Can Combustor with a Baffle Plate. Applied Thermal Engineering, 27, 788794. https://doi.org/10.1016/j.applthermaleng.2006.10.019

[7] Woodfield, P.L., Nakabe, K. and Suzuki, K. (2003) Numerical Study for Enhancement of Laminar Flow Mixing Using Multiple Confined Jet in a Micro-Can Combustor. International Journal of Heat and Mass Transfer, 46, 2655-2663. 
https://doi.org/10.1016/S0017-9310(03)00014-0

[8] Choi, H.S., Park, T.S. and Suzuki, K. (2008) Turbulent Mixing of a Passive Scalar in Confined Multiple Jet Flows of a Micro Combustor. International Journal of Heat and Mass Transfer, 51, 4276-4286.

https://doi.org/10.1016/j.ijheatmasstransfer.2007.12.017

[9] Choi, H.S. and Park, T.S. (2009) A Numerical Study for Heat Transfer Characteristics of a Micro Combustor by Large Eddy Simulation. Numerical Heat Transfer, Part A, 56, 230-245. https://doi.org/10.1080/10407780903163470

[10] Moghtaderi, B., Shames, I. and Djenidi, L. (2006) Microfluidic Characteristics of a Multi-Holed Baffle Plate Micro-Reactor. International Journal of Heat and Fluid Flow, 27, 1069-1077. https://doi.org/10.1016/j.ijheatfluidflow.2006.01.008

[11] Kim, W.H. and Park, T.S. (2016) Effects of Noncircular Air Holes on Reacting Flow Characteristics in a Micro Can Combustor with a Seven-Hole Baffle. Applied Thermal Engineering, 100, 378-391. https://doi.org/10.1016/j.applthermaleng.2016.02.004

[12] Fluent 6.3 User's Guide, Fluent Inc., Lebanon, New Hampshire, 2006.

[13] Haller. G. (2005) An Objective Definition of a Vortex. Journal of Fluid Mechanics, 525, 1-26. https://doi.org/10.1017/S0022112004002526

[14] Park, T.S. and Chung, Y.M. (2011) Turbulent Flow and Scalar Mixing of a Coaxial Injector Having Two Fluid Jets. Numerical Heat Transfer, Part A, 60, 197-211. https://doi.org/10.1080/10407782.2011.582410

\section{Submit or recommend next manuscript to SCIRP and we will provide best} service for you:

Accepting pre-submission inquiries through Email, Facebook, LinkedIn, Twitter, etc. A wide selection of journals (inclusive of 9 subjects, more than 200 journals)

Providing 24-hour high-quality service

User-friendly online submission system

Fair and swift peer-review system

Efficient typesetting and proofreading procedure

Display of the result of downloads and visits, as well as the number of cited articles

Maximum dissemination of your research work

Submit your manuscript at: http://papersubmission.scirp.org/

Or contact jamp@scirp.org 